\title{
ASSESSMENT OF FARM EFFICIENCY AND PRODUCTIVITY: A DATA ANALYSIS ENVELOPMENT APPROACH
}

\author{
Alina Syp ${ }^{1}$, Dariusz Osuch ${ }^{2}$ \\ ${ }^{1}$ Institute of Soil Science and Plant Cultivation - State Research Institute, Poland \\ ${ }^{2}$ Institute of Agricultural and Food Economics - National Research Institute, Poland \\ asyp@iung.pulawy.pl; dariusz.osuch@fadn.pl
}

\begin{abstract}
The objective of this article is to assess farm efficiency and productivity change in specialised large farms located in the region of Mazowsze and Podlasie during the years 2014 - 2016. For this, we used the non-parametric Data Envelopment Analysis (DEA) method and Malmquist index. Calculations were performed for three types of large farms classified as: field crop, pig and dairy. The study shows that mean technical efficiency of large field crop, pig and dairy farms amounted to 80,75 and $70 \%$, respectively. Technical inefficiency of field crop farms come mainly from scale efficiency, while of pig and dairy farms equally from pure technical and scale efficiency. It shows that inefficient management practices had an impact on farm performance. Therefore, in order to increase competitiveness of farms, an improvement of management practices is required. In the studied period the share of farms operating under increasing return was as follows: 67,72 , and $81 \%$, respectively for field crops, pig and dairy farms. The improvement of efficiency of those farms could be achieved by increasing their size. The results indicate that $8 \%$ of field crops, $12 \%$ of dairy and $16 \%$ of large pig farms were operating under decreasing scale efficiency, which means that those farms were operating above the optimal scale. The increase in their efficiency could be achieved through size reduction. In dairy farms the average annual productivity growth of $2 \%$ was recorded. In pig farms the productivity reduction of $5.4 \%$ was observed. It was the result of a decrease in technological efficiency.

Key words: technical efficiency, scale efficiency, farm size, pig farms, Data Envelopment Analysis, Malmaquist indices.
\end{abstract}

\section{Introduction}

Efficiency and productivity assessment for different sectors is very important in practice because it allows to control production. Therefore, it has become a key research field (Toma et al., 2017). There are two main approaches to measure productive efficiency i.e. parametric and non-parametric (Malana \& Malano, 2006). The estimation of parametric production function is based on stochastic frontier analysis (SFA), whereas the non-parametric on linear programming. Data Envelopment Analysis (DEA) estimates the efficiency using a non-parametric technique (Charnes, Cooper, \& Rhodes, 1978). The main advantage of DEA method is the requirement of only a limited number of a priori assumptions regarding the functional relationship between inputs and outputs overcoming some disadvantages of the parametric approach (Gadanakis et al., 2015). Therefore, DEA methods have been commonly applied to agricultural sector (Atici \& Podinovski, 2015; Cucchiela et al., 2018; Fogarasi \& Latruffe, 2009; Latruffe \& Desjuex, 2016; Malana \& Malano, 2006; Odeck, 2009; Parlinska \& Bezet, 2010; Syp et al., 2015; Toma et al., 2015; Toma et al., 2017; Vasiliev et al., 2008).

The aim of the present study was assessment of efficiency and productivity changes of large farms with different specializations in the region of Mazowsze and Podlasie in the years 2014 - 2016. To achieve this, we applied DEA models to the obtained efficiency scores and Malmquist indices to assess the productivity growth. Some analyses were performed to calculate the efficiency and productivity of Polish farms using simple standard efficiency indicators. However, to our knowledge, there are not existing studies in Poland analysing efficiency and productivity of the farms in the region of Mazowsze and Podlasie according to their economic size and specialization using DEA method. Thus, this paper makes an important contribution in this area. The article is structured as follows: the next section presents the materials and methods in detail; the third section presents efficiency results and discussion: and section 4 offers some concluding remarks.

\section{Materials and Methods}

Study area

To perform analysis based on Farm Accountancy Data Network (FADN), the region of Mazowsze and Podlasie has been selected which is assigned the number 795 (Commission Regulation 2009). The region includes four voivodships, namely: mazowieckie, podlaskie, lubelskie and łódzkie. This area has been chosen to study because: a) the utilized agricultural area (UAA) of this region accounts for about $37.2 \%$ of the country's UAA, b) $29 \%$ of the Polish population lives on this territory, c) $30 \%$ of Polish population is employed in agricultural sector, d) $32 \%$ of crops of basic cereals come from this region, e) $48 \%$ of cattle and $26 \%$ of pig stocks are located there (CSO, 2017). In 2016, in the region of Mazowsze and Podlasie the number of applicants who submitted applications for payments amounted to $43 \%$ of all applying, and the declared area in hectares was $36 \%$ of country UAA. Moreover, payments under the single area payment and greening were $37 \%$ of national expenditures in the frame of Common Agricultural Policy (CAP). 
Descriptive statistics of the FADN data set applied in DEA: 2014 - 2016

\begin{tabular}{|c|l|c|c|c|}
\hline \multirow{2}{*}{ No } & \multirow{2}{*}{ General information } & \multicolumn{3}{|c|}{ Type of farms } \\
\cline { 3 - 4 } & & Field crops & Dairy & Pigs \\
\hline 1 & Number of farms & 30 & 86 & 796285 \\
\hline 2 & Total output (PLN) & 861227 & 784318 & 44.0 \\
\hline 3 & UAA (ha) & 161.3 & 72.4 & 4981 \\
\hline 4 & Labour input (h) & 10285 & 6090 & 590798 \\
\hline 5 & Intermediate consumptions (PLN) & 466664 & 433474 & 2234212 \\
\hline 6 & Total assets (PLN) & 5704918 & 3563151 & \\
\hline
\end{tabular}

Notes: PLN - Polish currency. UAA - utilised agricultural area. $\mathrm{H}$ - labour input in working hours. Source: authors' calculations based on the FADN data.

\section{DEA model specification}

The DEA methods were used to assess farm efficiency and productivity changes in the region of Mazowsze and Podlasie. DEA constructs the best practice frontier in the given set of data so the best performing farms form the envelope (i.e. the frontier). Next, it calculates the farm efficiency scores in respect to this frontier (Charnes, Cooper, \& Rhodes, 1978). The concept of efficiency relates to the distance of the farm from the production frontier: a small distance indicates high efficiency, whereas a large distance presents low efficiency. Efficiency (total, pure and scale) indicators range from 0 to 1 . The fully efficient farm received score 1 (i.e. on the frontier) and a larger score presents a higher efficiency. The score lower than 1 points out to what level the inputs could be reduced and still produce the same quantity of output. A farm technical efficiency (TE) score was calculated under the assumption of constant returns to scale (CRS). The TE was divided into two scores: pure technical efficiency (PTE) and scale efficiency (SE). PTE was estimated under variable returns to scale (VRS) and referred to management practices. SE, at the same time, was the ratio between TE and PTE and presented the potential scale economies accessible to the farm.

The DEA has two alternative orientations: input and output (Charnes, Cooper, \& Rhodes, 1978). The input-oriented model estimates the proportional reduction of applied inputs while output remains unchanged. The concept of output-oriented model is to using the existing technology to produce the highest level of outputs from a given combination of inputs (Toma et al., 2017). Some researchers stated that input-orientated model is more appropriate for agriculture because it depends on limited inputs (Malana \& Malano, 2006; Toma et al., 2015) and in the production process farmers have more control over input rather than output (Syp et al., 2015). Others pointed out that it is easier for farmers to adjust their final outputs than the volume of inputs and, therefore, selected output-oriented model (Fogarasi \& Latruffe, 2009). However, Coelli et al. (2005) noticed that outcomes from both models are comparable, therefore, the choice of orientation is not crucial. Additionally, DEA enables to estimate under which returns to scale each farm operates: constant (CRS), decreasing (DRS) or increasing (IRS) ones. Our analysis proceeded in the following order: first the efficiency scores were calculated by using technical, pure technical and scale efficiency. The second step included the estimation of farms' scale of operations. The third - the use of Malmquist productivity indices to calculate of productivity changes. The Malmquist total productivity index (TFP) was divided into the technological change index (TC), which assessed the shift of the frontier over time, and TE change index, which measured variation in TE efficiency (Färe et al., 1992). Next, TE change index was spread out into change of PTE and SE. Scores equal to 1 presented no change, higher than 1 - development, while lower than 1 - regress. The average change indices were expressed as geometrical means.

\section{Data sets and variables}

The study employed data from the Polish Farm Accountancy Data Network (FADN) for the period of 2014 - 2016. The database provides information on the physical and economic performance of farms in Poland. The research covered only those farms that were in the FADN system throughout the whole period taken into account. The analysis was performed for three types of farms based on their production specialisation: field crop farms (TF1), dairy farms (TF 5) and pig farms (TF 71). The criterion for classification of the agricultural holdings is that at least $66 \%$ of standard output (SO) from specific production of type farm must contribute to the total output of the farm. Then, from the group of farms selected for further analysis only large farms were chosen - with SO values more than 100 and less than 500 EUR K. 
The analysed sample consisted of 185 farms, 30 of which were field crops, 86 dairy and 69 pig farms. The dependent variable in the input-oriented DEA models was total output (SE131) expressed in PLN (Polish currency). As inputs we selected and applied: labour (SE011) defined in work hours, total UAA (SE025) in hectares, total assets (SE436) total intermediate consumption (SE275). Values of total assets and intermediate consumption were presented in zloty.

Table 1 presents some descriptive statistics of the variable applied to the DEA model. During the studied period, on average, field crop farms had the highest UAA, labour input, total assets and output compared to livestock farms. The pig farms used the least labour, had the lowest total assets, and the highest intermediate consumption of all three specializations. The dairy farm values of total output and intermediate consumption were the lowest in comparison with the data of other farm types.

The DEAP software was used to calculate the efficiency and productivity change indices of selected farms.

\section{Results and Discussion}

The first step of our analysis involved calculation of the technical efficiency in order to provide information for potential improvements. The summary results of the DEA efficiency scores are presented in Tables 2 - 4. Because the maximum score of TE was 1 , only minimum values are presented.
In the analysed period, the field crop farms were more technically efficient than dairy and pig farms. In 2014 - 2016 the field crop farms had a mean technical efficiency of 0.799 , meaning they could reduce their inputs by $20 \%$ and still produce the same level of outputs.

In pig and dairy farms the reduction mean potential for input savings amounted to 25 and $30 \%$, respectively. For individual years, we recorded the variations in average scores. In 2015, the highest scores were recorded for field crop and pig farms. It was mostly due to good climatic conditions for cereal cultivation which is mainly grown in these types of farms. However, the drought in the second part of 2015 caused very bad conditions for regrowth of vegetation on pastures, and resulted in lower technical efficiency scores of dairy farms. In the period of $2014-2016$, the average coefficients of variation in all farm groups were on the same level, i.e. 0.21 , which indicates the comparable distribution of technical efficiency scores through the samples. Similar rankings to technical efficiency averages were noted for PTE and SE indicators. However, only in the crop field farms the value of PTE increased year after year, which indicates that the management has been constantly improved.

Table 5 presents the share of farms operating under CRS, IRS and DRS. Our results show that the filed crop farms are more scale efficient than livestock farms ( 26 v. 7 v. 12). In the studied period all types of farms were mostly operating under IRS indicating that

Descriptive results of field crop farms' efficiency estimates

Table 2

\begin{tabular}{|c|c|c|c|c|}
\hline Efficiency scores & Mean & Standard deviation & Minimum & Coefficient of variation \\
\hline \multicolumn{5}{|c|}{ Technical efficiency } \\
\hline 2014 & 0.800 & 0.156 & 0.435 & 0.195 \\
\hline 2015 & 0.819 & 0.179 & 0.501 & 0.219 \\
\hline 2016 & 0.779 & 0.187 & 0.388 & 0.240 \\
\hline $2014-2016$ & 0.799 & 0.175 & 0.388 & 0.219 \\
\hline \multicolumn{7}{|c|}{ Pure technical efficiency } \\
\hline 2014 & 0.882 & 0.115 & 0.624 & 0.130 \\
\hline 2015 & 0.908 & 0.122 & 0.615 & 0.134 \\
\hline 2016 & 0.911 & 0.117 & 0.570 & 0.132 \\
\hline $2014-2016$ & 0.901 & 0.118 & 0.570 & 0.121 \\
\hline & & Scale efficiency & & 0.134 \\
\hline 2014 & 0.904 & 0.110 & 0.612 & 0.176 \\
\hline 2015 & 0.895 & 0.120 & 0.653 & 0.147 \\
\hline 2016 & 0.850 & 0.150 & 0.502 & 0.502 \\
\hline
\end{tabular}

Source: authors' calculations based on the FADN data. 


\section{Descriptive results of dairy farms' efficiency estimates}

\begin{tabular}{|c|c|c|c|c|}
\hline \multirow{2}{*}{ Efficiency scores } & Mean & Standard deviation & Minimum & Coefficient of variation \\
\hline \multicolumn{5}{|c|}{ Technical efficiency } \\
\hline 2014 & 0.719 & 0.156 & 0.310 & 0.218 \\
\hline 2015 & 0.654 & 0.147 & 0.338 & 0.225 \\
\hline 2016 & 0.718 & 0.167 & 0.276 & 0.232 \\
\hline $2014-2016$ & 0.699 & 0.135 & 0.276 & 0.193 \\
\hline \multicolumn{5}{|c|}{ Pure technical efficiency } \\
\hline 2014 & 0.875 & 0.119 & 0.616 & 0.136 \\
\hline 2015 & 0.806 & 0.130 & 0.516 & 0.162 \\
\hline 2016 & 0.822 & 0.125 & 0.402 & 0.152 \\
\hline $2014-2016$ & 0.836 & 0.128 & 0.402 & 0.153 \\
\hline & & Scale efficiency & & 0.178 \\
\hline 2014 & 0.825 & 0.147 & 0.310 & 0.162 \\
\hline 2015 & 0.813 & 0.132 & 0.474 & 0.139 \\
\hline 2016 & 0.868 & 0.121 & 0.510 & 0.162 \\
\hline $2014-2016$ & 0.836 & 0.135 & 0.474 & \\
\hline
\end{tabular}

Source: authors' calculations based on the FADN data.

they were too small. Thus, the important conclusion of these outcomes is that these farms can achieve efficiency growth by increasing in size. The results also indicate that the shares of farms operating under
DRS were as follows: 8,12 and $16 \%$, respectively, for field crop, dairy and pig farms. This implies that these farms were too large and could gain efficiency by size reduction.

\section{Descriptive results of pig farms' efficiency estimates}

\begin{tabular}{|c|c|c|c|c|}
\hline Efficiency scores & Mean & Standard deviation & Minimum & Coefficient of variation \\
\hline \multicolumn{5}{|c|}{ Technical efficiency } \\
\hline 2014 & 0.789 & 0.140 & 0.541 & 0.178 \\
\hline 2015 & 0.750 & 0.144 & 0.449 & 0.193 \\
\hline 2016 & 0.703 & 0.169 & 0.399 & 0.240 \\
\hline $2014-2016$ & 0.747 & 0.156 & 0.399 & 0.209 \\
\hline \multicolumn{5}{|c|}{ Pure technical efficiency } \\
\hline 2014 & 0.879 & 0.118 & 0.571 & 0.134 \\
\hline 2015 & 0.863 & 0.121 & 0.604 & 0.141 \\
\hline 2016 & 0.845 & 0.135 & 0.527 & 0.160 \\
\hline $2014-2016$ & 0.862 & 0.126 & 0.527 & 0.146 \\
\hline \multicolumn{5}{|c|}{ Scale efficiency } \\
\hline 2014 & 0.898 & 0.103 & 0.580 & 0.115 \\
\hline 2015 & 0.872 & 0.120 & 0.449 & 0.138 \\
\hline 2016 & 0.832 & 0.142 & 0.544 & 0.170 \\
\hline $2014-2016$ & 0.867 & 0.126 & 0.449 & 0.145 \\
\hline
\end{tabular}

Source: authors' calculations based on the FADN data. 
Tables 6-8 present the average TFP change indices as well as the average changes in TFP components for all types of the studied farms.

The average TFP changes were as follows: 0.948 , 0.998 and 1.020, respectively, for pig, crop field and dairy farms. The figures indicate that productivity in pig farms decreased by $5.2 \%$ for the yearly scores between the first year and the next, whereas in the field crop farms only by $0.2 \%$. The small increase of TFP was recorded for dairy farms and equalled by $0.2 \%$ each year. The decrease of TFP indices in pig and field crop farms was mainly due to the technological deterioration because the values of TE change indexes were above one. The further breakdown of TE change index shows that the main source of efficiency increased in pig farms was growth of SE by $4.3 \%$ and TC by $2.2 \%$. In the field crop farms TE changes were only due to the growth of SE $(+3.6 \%)$ which offset the decline of PTE indices. In the dairy farms the rise of TE change index resulted from the technical improvement $(+3.3 \%)$ because the SE index dropped $(-2.7 \%)$. This implies that farmers ameliorate their farming practices by reducing the input used and scale efficiency.

The input and output data applied in our study are consistent with the data applied by Dakpo et al. (2017), Fogarsi and Latruffe (2009), Ghali et al. (2016), Latruffe and Desjeux (2016), and Vasiliev et al. (2008). Latruffe and Desjeux (2016) calculated efficiency and productivity indices for different farm types in France for the period of $1990-2006$. As the UAA averages of field crop and dairy farms in France are similar to the area of large field crop and dairy Polish farms in the region of Mazowsze and Podlasie, we could compare our results. Field crop farms in France obtain lower mean scores of TC (0.499 v. 0.799) and PTE (0.531 v. 0.901). The high differences between those scores resulted from a greater diversification in the selected French sample. The output of Polish farms was twice higher than that of French farms. However, the average SE score of French farms was $4.5 \%$ higher than the one recorded in our analysis. This confirms a better use of the inputs in the French field crop farms. The difference between efficiency indicators of dairy farms was much lower i.e. TC (0.669 v. 0.699), PTE (0.696 v. 0.836$)$ and SE (0.952 v. 0.836). This data proves that the management of French dairy farms has better adjusted inputs to scale production. There were very small differences between changes of TFP, TE and TC of field crop and dairy farms in the studied countries. However, in French farms all scores had values slightly below 1, whereas in Poland above 1 . The presented data show that the improvement of Polish farms' performance is still continuing when in French farms deterioration has started. Based on similar data inputs, Dakpo et al. (2017) assessed productivity changes and its components for several farm types in French agriculture in $2002-2014$. The

\section{The proportion of farms according to scale - Constants, Increasing and Decreasing - as an average 2014 - 2016}

\begin{tabular}{|c|l|c|c|c|}
\hline \multirow{2}{*}{ No } & \multirow{2}{*}{ Share of farms operating under: } & \multicolumn{3}{|c|}{ Type of farms } \\
\cline { 3 - 5 } & & Field crops & Dairy & 12 \\
\hline 1 & Constant (\%) & 26 & 7 & 72 \\
\hline 2 & Increasing (\%) & 67 & 81 & 16 \\
\hline 3 & Decreasing (\%) & 8 & 12 & \\
\hline
\end{tabular}

Source: authors' calculations based on the FADN data.

\section{Productivity change indices of field crop farms during 2014 - 2016}

\begin{tabular}{|c|l|c|c|c|c|}
\hline No & \multicolumn{1}{|c|}{ Average productivity change indices } & Mean & Minimum & Maximum & Standard deviation \\
\hline 1 & TE change index & 1.020 & 0.804 & 1.418 & 0.116 \\
\hline 2 & PTE change index & 0.984 & 0.832 & 1.113 & 0.056 \\
\hline 3 & SE chanage index & 1.036 & 0.862 & 1.382 & 0.093 \\
\hline 4 & Technological change index & 0.978 & 0.837 & 1.081 & 0.055 \\
\hline 5 & Malmquist productivity change index & 0.998 & 0.738 & 1.313 & 0.125 \\
\hline
\end{tabular}

The averages of productivity change indices are the geometrical means.

Source: authors' calculations based on the FADN data. 
Productivity change indices of dairy farms during 2014 - 2016

\begin{tabular}{|l|l|c|c|c|c|}
\hline No & \multicolumn{1}{|c|}{ Average productivity change indices } & Mean & Minimum & Maximum & Standard deviation \\
\hline 1 & TE change index & 1.005 & 0.660 & 1.809 & 0.146 \\
\hline 2 & PTE change index & 1.033 & 0.785 & 1.526 & 0.094 \\
\hline 3 & SE chanage index & 0.973 & 0.578 & 1.186 & 0.084 \\
\hline 4 & Technological change index & 1.016 & 0.912 & 1.118 & 0.050 \\
\hline 5 & Malmquist productivity change index & 1.020 & 0.604 & 1.762 & 0.133 \\
\hline
\end{tabular}

The averages of productivity change indices are the geometrical means.

Source: authors' calculations based on the FADN data.

Productivity change indices of pig farms during 2014 - 2016

Table 8

\begin{tabular}{|l|l|c|c|c|c|}
\hline No & \multicolumn{1}{|c|}{ Average productivity change indices } & Mean & Minimum & Maximum & Standard deviation \\
\hline 1 & TE change index & 1.066 & 0.842 & 1.290 & 0.0974 \\
\hline 2 & PTE change index & 1.022 & 0.874 & 1.212 & 0.072 \\
\hline 3 & SE chanage index & 1.043 & 0.674 & 1.546 & 0.075 \\
\hline 4 & Technological change index & 0.890 & 0.369 & 1.116 & 0.091 \\
\hline 5 & Malmquist productivity change index & 0.948 & 0.723 & 1.173 & 0.087 \\
\hline
\end{tabular}

The averages of productivity change indices are the geometrical means.

Source: authors' calculations based on the FADN data.

results of this study for field crop, dairy and pig farms were compared with our findings because the average of farms' UAA were alike. The values for French field crop farms were higher than our scores of $16.3 \%$, $16.7 \%, 3.6 \%$ and $5.1 \%$, respectively for TFP, TE, TC and PTE changes. Whereas, smaller differences were recorded for dairy farms. In those farms, the values of PTE, TC and SE were higher, respectively, by 2.1, 5 , and $2.9 \%$. The TFP and TE got lower values of 2.9 and $2.7 \%$, respectively. The scores for pig farms differ more than in already presented farms. The higher changes were recorded for PTE $(+13.4 \%)$ and TE $(+17.4)$, lower for TC $(-1.7 \%)$, PTE $(-1.8 \%)$ and SE $(-3.1 \%)$. In both countries the increase of SE in dairy farms was recorded. However, the greater growth of SE changes in French dairy farms indicated that French farmers limited input in greater extent. The drop of SE in the field crop and pig farms showed that farmers in the region of Mazowsze and Podlasie had to adopt the input saving technique better. The value of SE changes from Latruffe and Desjeux (2016), and Dakpo et al. (2017) studies show that even they analysed data from different years the SE changes in France were higher than in Poland.

So, this confirms that French farms better control and limit the inputs. Ghali et al. (2016) measured TE and PTE of French field crop and dairy farms based on data from 2010. The average UAA of filed crop farms was 148 ha, whereas of dairy farms - 96 ha, i.e. $33 \%$ larger than Polish dairy farms. So the data from this study could be comparable with our outcomes. The average TE of Polish crop field and dairy farms were higher respectively by 14.9 and $4 \%$. The average PTE score of field crop farms was higher by $9.1 \%$, whereas in dairy farms lower by $0.4 \%$. Despite the fact that both PTE scores were high and there was little difference between them, there is a place for improvement of management practices. In Vasilev et al. (2008) studies the efficiency scores were calculated for Estonian grain farms in which UAA were above 180 ha. Therefore, all the results of this study could be referred to our analysis performed for the large filed crop farms. The TE of those farms ranged from 0.70 to 0.78 . Where as in the region of Mazowsze and Podlasie it varied from 0.78 to 0.82 . The difference between PTE amounted to 5\%. There was no difference between SE in that group of farms. Results of our analysis show that a higher percentage of farms working under IRS and CRS was recorded in the region of Mazowsze and Podlasie than in Estonia. Fogarsi and Latruffe (2009) compared the technical efficiency in dairy farming of France and Hungary in 2001 - 2006. Our studies cover a later period but results could be compared. The average TE efficiency 
for the whole period of Polish dairy farms (0.699) was lower than for France (0.723) and Hungary (0.791). Similar differences were in SE scores. There was no difference between PTE values of Hungary and Polish farms. The mainly difference in TE comes from SE.

\section{Conclusions}

1. The results of this study contribute to the literature on efficiency and productivity measurement in the agricultural sector by applying the DEA method to calculate efficiency and Malmquist index to estimate the productivity changes.

2. This study was the first to provide efficiency and productivity estimates for large field crop, dairy and pig farms based on FADN data in the region of Mazowsze and Podlasie during the years 2014 - 2016. All calculated indices for this region are consistent with the results obtained in the previous studies.

3. The mean potential for input savings has been approximately $20 \%$ for large field crop farms, $25 \%$ for pig and $30 \%$ for dairy farms in the region of Mazowsze and Podlasie. Inefficiency of field crop farms comes mainly from scale efficiency, and of pig and dairy farms equally from pure technical and scale efficiency.

4. The high percentage of studied farms operated under increasing returns to scale. The growth of their efficiency could be realized by an increase of farm size.

5. In the studied period, only in dairy farms the average productivity growth of $2 \%$ per year was recorded. This increase was due to both technical and technological efficiency improvements. In pig farms the productivity reduction of $5.4 \%$ was observed. It was the result of a decrease in technological efficiency. There was no change in the productivity of field crop farms.

\section{Acknowledgements}

The study has been financed by The National Centre for Research and Development within the project Support for low carbon agriculture - able to adapt to observed climate change in the perspective of 2030 and 2050 (acronym LCAgri), contract number: BIOSTRATEG1/271322/3/NCBR/2015.

\section{References}

1. Atici, K.B., \& Podinovski, V.V. (2015). Using data envelopment analysis for the assessment of technical efficiency of units with different specialisations: an application to agriculture. Omega, 54, 72-87. DOI: 10.1016/j.omega.2015.01.015.

2. Charnes, A., Cooper, W.W., \& Rhodes, E. (1978). Measuring the efficiency of decision making units. European Journal of Operational Research, 2, 429-444.

3. Coelli, T., Rao, D., O’Donnell, C., \& Battese, G. (2005). An Introduction to efficiency and productivity analysis. Second Edition. Springer. New York.

4. Central Statistical Office. (2017). Statistical Yearbook of the Regions - Poland. Warszawa.

5. Cucchiella, F., D’Adamo, I., Gastaldi, M., \& Miliacca, M. (2018). Efficiency and allocation of emission allowances and energy consumption over more sustainable European economies. Journal of Cleaner Production, DOI: 10.1016/j.jclepro.2018.02.079.

6. Färe, R., Grosskopf, S., Lindgren, B., \& Roos, P. (1992). Productivity changes in Swedish pharmacies 1980-1989: A non-parametric approach. Journal of Productivity Analysis, 3(1-2), 85-101.

7. Fogarasi, J., \& Latruffe, L. (2009). Technical Efficiency in dairy farming: A comparison of France and Hungry in 2001-2006. Studies in Agricultural Economics, 110, 75-84.

8. Gadanakis, Y., Bennett, R., Park, J., \& Areal, F.J. (2015). Evaluating the sustainable intensification of arable farms. Journal of Environmental Management, 150, 288-298. DOI: 10.1016/j.jenvman.2014.10.005.

9. Latruffe, L., \& Desjuex, Y. (2016). Common Agricultural Policy support. technical efficiency and productivity change in French agriculture. Review of Agricultural. Food and Environmental Studies, 97, 15-28. DOI: 10.1007/s41130-016-0007-4.

10. Malana, M.N., \& Malano., M.H. (2006). Benchmarking productive efficiency of selected wheat areas in Pakistan and India using data envelopment analysis. Irrigation and drainage, No, 55, 383-394. DOI: 10.1002/ird.264.

11. Odeck, J. (2009). Statistical precision of DEA and Malmquist indices: A bootstrap application to Norwegian grain producers. Omega, 37, 1007-1017. DOI: 10.1016/j.omega.2008.11.003.

12. Official Journal of the European Commission. (2009). Commission Regulation (EC) No 1291/2009 of 18 December 2009 concerning the selection of returning holdings for the purpose of determining incomes of agricultural holdings, No, 347. pp. 14-21.

13. Parlinska, M., \& Bezet, A. (2010). Efficiency of the Polish wholesale markets- validation based on the Data Envelopment Analysis. Roczniki Naukowe SERiA, 10 (5), pp. 122-124. 
14. Syp, A., Faber, A., Borzecka-Walker, M., \& Osuch, D. (2015). Assessment of greenhouse gas emissions in winter wheat farms using Data Envelopment Analysis approach. Polish Journal of Environmental Studies, 24 (5), 2197-2203. DOI: 10.15244/pjoes/39682.

15. Toma, E., Dobre, C., Dona, I., \& Cofas, E. (2015). DEAApplicability in assessment of agriculture efficiency on areas with similar geographically patterns. Agriculture and Agricultural Science Procedia, 6, 704-711.

16. Toma, P., Miglietta, P.P., Zurlini, G., Valente, D., \& Petrosillo, I. (2017). A non-parametric bootstrapdata envelopment analysis approach for environmental policy planning and management of agricultural efficiency in EU countries. Ecological Indicators, 83, 132-143. DOI: 0.1016/j.ecolind.2017.07.049.

17. Vasiliev, N., Astover, A., Mõtte, M., Noormets, M., Reintam, E., \& Roostalu, H. (2008). Efficiency of Estonian grain farms in 2000-2004. Agricultural and food science, 17, 31-40. 